OPEN ACCESS

Edited by:

Deseada Parejo,

Universidad de Extremadura, Spain

Reviewed by:

Michael P. Ward,

University of Illinois at

Urbana-Champaign, United States

Aurore Ponchon,

University of Aberdeen,

United Kingdom

*Correspondence:

Jennifer Morinay

jennifer.morinay@gmail.com

Specialty section:

This article was submitted to Behavioral and Evolutionary Ecology,

a section of the journal

Frontiers in Ecology and Evolution

Received: 14 September 2017 Accepted: 11 December 2017 Published: 30 January 2018

Citation:

Morinay J, Forsman JT, Kivelä SM, Gustafsson L and Doligez B (2018)

Heterospecific Nest Site Copying Behavior in a Wild Bird: Assessing the Influence of Genetics and Past Experience on a Joint Breeding Phenotype. Front. Ecol. Evol. 5:167. doi: 10.3389/fevo.2017.00167

\section{Heterospecific Nest Site Copying Behavior in a Wild Bird: Assessing the Influence of Genetics and Past Experience on a Joint Breeding Phenotype}

\author{
Jennifer Morinay ${ }^{1,2 *}$, Jukka T. Forsman ${ }^{3}$, Sami M. Kivelä ${ }^{3,4}$, Lars Gustafsson ${ }^{2}$ and \\ Blandine Doligez
}

${ }^{1}$ Laboratoire de Biométrie et Biologie Evolutive, Centre National de la Recherche Scientifique UMR 5558, University of Lyon-Université Claude Bernard Lyon 1, Villeurbanne, France, ${ }^{2}$ Department of Ecology and Evolution, Animal Ecology, Evolutionary Biology Centre, Uppsala University, Uppsala, Sweden, ${ }^{3}$ Department of Ecology and Genetics, University of Oulu, Oulu, Finland, ${ }^{4}$ Department of Zoology, Institute of Ecology and Earth Sciences, University of Tartu, Tartu, Estonia

Breeding site selection is often a joint decision of pair members in species with biparental care and the experience of both pair members may influence the use of information for site selection. Nevertheless, quantitative genetics of joint information use for site selection remains unexplored so far. We used an experimental approach to quantify the relative importance of genetics (heritability) and past experience (age, familiarity with the environment, previous breeding success, previous information use) in heterospecific social information use for nest site selection in wild collared flycatchers (Ficedula albicollis). Flycatchers collect social information from resident tits for nest site selection. We created an apparent preference of tits for a novel nest site feature and recorded choices of flycatchers (copying or rejecting the tit preference). Copying behavior was stronger for naive individuals but also differed between years, which could be explained by contrasting seasonality in the demonstrator species. Past experience as reflected by age affected subsequent use of social information: pairs with a yearling male were more likely to copy the heterospecific preference than pairs with older immigrant males. There was no general pattern in successive individual choices over the years. Accordingly, individual repeatability in copying tit preference was very low. At the pair level, we estimated sex-specific direct and indirect genetic effects on the joint nest site decision and found no sex-specific heritability and no cross-sex genetic correlation. Our results confirm the importance of past experience for social information use and suggest that social information use is highly plastic and most likely not genetically inherited in collared flycatchers. Whether individuals use social information should be related to environmentally-induced changes in the quality of information and thus be context-dependent. Selection may therefore act on the ability to optimally use social information in varying environments and on the processes underlying such adjustment, such as learning, rather than the use of information itself.

Keywords: social information, breeding site selection, collared flycatcher, Ficedula albicollis, heritability, indirect genetic effects, quantitative genetics, past experience 


\section{INTRODUCTION}

In species with biparental care, many breeding traits can be considered as joint (or interacting) phenotypic traits (Moore et al., 1997) because both partners may influence reproductive behaviors such as egg laying, territory defense, breeding site selection, etc. (e.g., Brommer and Rattiste, 2008; Hall et al., 2013). In particular, the choice of a breeding site is likely to be a joint phenotypic decision made by both the male and the female (Loukola et al., 2012), and it will strongly affect pair reproductive success (Danchin et al., 2008; Doligez and Boulinier, 2008). In spatio-temporally varying environments, this joint decision may involve the use of social information, that is, information derived from the presence, performance, or actions of other individuals, to reduce the uncertainty about habitat quality (Danchin et al., 2004; Dall et al., 2005). Because breeding constraints (on e.g., extra-pair or mating opportunities, intra-sexual competition) often differ between sexes (Trivers, 1972; Arnqvist and Rowe, 2005), males and females may use different social information sources or use the same information differently when decisions are made independently (e.g., for dispersal decisions Doligez et al., 1999; for mate-choice Kniel et al., 2015). Nevertheless, male and female information use may interact to produce a joint breeding site decision. If the use of social information is heritable, through e.g. the influence of genes on behaviors shaping information gathering and use (e.g., Fidler et al., 2007 for exploration behavior; Foucaud et al., 2013 for information use in spatial learning), the choice of a breeding site can be seen as the result of the interaction between male and female genotypes. However, very little is known about the relative phenotypic and genetic contribution of the male and the female in a breeding pair to the use of social information for breeding site choice.

The massive evidence for social information use in breeding site selection (reviewed by Seppänen et al., 2007; Valone, 2007; Avarguès-Weber et al., 2013) suggests that this behavior is often favored by natural selection, but very little is known about its genetic basis. The only study (to our knowledge) that provided evidence for the role of genetics in social information use was conducted in a laboratory population of Drosophila melanogaster and involved genetic polymorphism at one locus (Foucaud et al., 2013). Yet, understanding the genetic architecture of social information use for breeding site selection requires assessing its heritability in wild populations. Importantly, social information use is often context-dependent and may depend on age (e.g., Dugatkin and Godin, 1993), sex (e.g., Kniel et al., 2015), personality (e.g., Marchetti and Drent, 2000; Kurvers et al., 2010), or individual's personal experience (e.g., Danchin et al., 1998; Kendal et al., 2004; van Bergen et al., 2004; and see Valone, 2007). The benefits of social information use may indeed change over a lifetime, as individuals gather more experience and thus personal information (reviewed in Kendal et al., 2005; Valone, 2007). A strong contribution of individual experience to social information use can therefore be expected for breeding site selection, and both partners' experience may interact when the breeding site choice represents a joint decision.

Reproductive decisions are thought to be highly plastic in response to environmental variations (Lynch and Walsh,
1998; Meffert et al., 2002; Stirling et al., 2002). Consequently, heritability estimates of behaviors linked to reproduction are usually relatively low to moderate (on average 0.3; Stirling et al., 2002). Besides strong phenotypic plasticity, low heritability estimates in reproductive behaviors can be due to strong directional selection on traits tightly linked to fitness, depleting additive genetic variance (Gustafsson, 1986; Roff, 1997; Merilä and Sheldon, 1999) and/or to the presence of non-additive genetic effects masking additive genetic effects (Meffert et al., 2002). Such non-additive genetic effects arise when (1) the phenotype of a focal individual is affected by interactions with other individuals and (2) this effect is heritable. This defines socalled indirect genetic effects, that are effects of genotypes of other individuals on the phenotype of the focal individual (reviewed by Moore et al., 1997; Bijma, 2014). Among indirect genetic effects are the well-studied maternal effects, i.e., the effects of the mother's genotype on the phenotype of its offspring (McAdam et al., 2014).

Indirect genetic effects are often overlooked in quantitative genetics studies in the wild, but ignoring these effects can result in over- or under-estimating heritability estimates and can therefore impact predictions about the micro-evolutionary potential of the trait considered (Wolf et al., 1998; Bijma, 2014; McAdam et al., 2014; Wolak and Keller, 2014). Indirect genetic effects may particularly be expected for joint phenotype as they are likely affected by the genotypes of both pair members. For example, in Larus canus (common gulls), laying date depended on direct female but also indirect male genetic effects. Male genes could influence the female laying date through genetically determined pre-copulatory behaviors such as mate guarding or feeding for example (Brommer and Rattiste, 2008). Importantly, direct female and indirect male genetic effects interacted negatively, resulting in a negative cross-sex genetic correlation that could be due to pleiotropy: genes promoting earlier laying in females probably promoted delayed laying of partners when expressed in males (Brommer and Rattiste, 2008). This result revealed a reproductive conflict between sexes at the genetic level, which maintained phenotypic variation in laying date in the population and constrained evolution toward earlier laying date, despite strong selection for this trait in this species (Brommer and Rattiste, 2008).

Here, we estimated the phenotypic (in terms of overall individual experience) and genetic contributions of males and females to the use of social information for joint nest site selection in a patchy population of collared flycatchers Ficedula albicollis. Social information has been shown to play a critical role for habitat quality assessment and settlement decisions in the Ficedula species. Flycatchers use both conspecific and heterospecific density, reproductive investment, or success for breeding habitat selection and adjustment of reproductive effort (Doligez et al., 1999, 2002, 2004a; Forsman et al., 2008, 2012), which results in fitness benefits (Forsman et al., 2002). Experiments have also shown that flycatchers copy the (apparent) nest site preference of their main heterospecific competitors, great tits Parus major and blue tits Cyanistes caeruleus (Seppänen and Forsman, 2007; Seppänen et al., 2011). Nevertheless, these studies also report high among-individual variability in the use of 
social information (Jaakkonen et al., 2013). The use of different sources of social information in the collared flycatcher and its among-individual variation previously described thus make this species a highly suitable model to assess the repeatability, heritability, and the importance of personal experience in breeding habitat selection decisions based on social information.

Over 5 years, we experimentally provided individuals with a source of social information independent from actual site quality using an artificial nest site feature design previously successfully used in this system (Seppänen and Forsman, 2007; Seppänen et al., 2011; Jaakkonen et al., 2013, 2015; Forsman et al., 2014). Using a quantitative genetic approach (Wilson et al., 2010), we simultaneously explored the relative contribution of female and male (i) overall experience (age, familiarity with the environment, previous experience with the experimental design, and previous breeding success) and (ii) direct and indirect additive genetic effects on the joint decision to use the manipulated information source for nest site choice. Individuals with low personal information are expected to rely more on social information for decision-making, provided that such information is available to them, compared to individuals with high personal information (Reed et al., 1999; Danchin et al., 2001; Valone, 2007; Doligez and Boulinier, 2008). Therefore, pairs with young and/or naive individuals are expected to show higher propensity to use our manipulated social information than pairs with older individuals and/or individuals more familiar with the environment or with the experimental design, because our experimental social information was provided for all individuals at the time of settlement. Among individuals tested over several years, past reproductive success and past use of the manipulated information may have interactive effects on subsequent nest site decisions. Finally, in line with previous studies showing highly context-dependent social information use (reviewed in Kendal et al., 2005; e.g., Forsman and Seppänen, 2011), we expect that the use of social information for nest site selection would show relatively low individual repeatability and joint heritability.

\section{MATERIALS AND METHODS}

\section{Study System and Population Monitoring}

We conducted the nest site choice experiment from spring 2012 to 2016 on a population of collared flycatchers breeding on the island of Gotland (Sweden, $57^{\circ} 03^{\prime} \mathrm{N}, 18^{\circ} 18^{\prime} \mathrm{E}$ ). Flycatchers are cavity nesters and readily accept to breed in artificial nest boxes, allowing detailed breeding data and identity of breeders to be collected on a large number of nests. Nest boxes have been provided in 18 forest patches separated by habitat unsuitable for breeding in this species, with inter-patch distances spanning from several hundreds of meters up to $12 \mathrm{~km}$. The experiment was performed in 12 patches in 2012, 17 patches in 2013, 2014 and 2015 , and 16 patches in 2016. Forest patches varied in size and included between 29 and 106 nest boxes each, with an average nest box density of 5 boxes/ha. During the breeding season, approximately $1 / 3$ of the boxes are occupied by flycatchers, $1 / 3$ by tits (of which $3 / 4$ are great tits and $1 / 4$ blue tits) and $1 / 3$ remains empty.
Flycatchers have been found to use conspecific cues from the previous year (presence and/or reproductive success) for departure (Doligez et al., 1999, 2002) and settlement decisions both at large (Alatalo et al., 1982; Doligez et al., 2002, 2004a) and small spatial scales (Jaakkonen et al., 2013; Kivelä et al., 2014). In addition, flycatchers are migratory and arrive on the breeding grounds from late April to late May, when most tits have already started laying or incubating. Flycatchers use information on the presence and reproductive investment of their main competitors, resident tit species, collected at the beginning of the breeding season to adjust settlement and reproductive decisions (Seppänen and Forsman, 2007; Forsman et al., 2008, 2012; Kivelä et al., 2014). All flycatchers breeding in nest boxes in the study area were captured inside boxes, either at midincubation (females) or at mid- to late chick rearing period (males). Because of early brood failure, adult capture rate was thus sex-biased (approximately $90 \%$ of females vs. $70 \%$ of males caught in boxes every year). Caught individuals were identified or ringed if previously unringed (approximately $40 \%$ of breeders every year), weighed, measured, and aged in the field based on plumage criteria (yearlings vs. older individuals; Svensson, 1992). All nestlings in nest boxes were ringed during the rearing period. This information, as part of the long-term monitoring of the population since 1980, allowed the construction of a social pedigree of the flycatcher population (see below in the Statistical Analysis section).

\section{Nest Box Choice Experiment}

The experiment was conducted from early April (i.e., just before tit settlement) to early June (i.e., after the settlement of the last flycatcher pairs). We manipulated a source of heterospecific social information available to collared flycatchers by creating an apparent preference of tits for a novel nest site feature. This artificial feature was a white geometric symbol, either a triangle or a circle, attached around the entrance hole of the nest box. To create an apparent preference of tits at the patch scale, the same symbol was systematically attached to all boxes occupied by great and blue tits in a given patch (Figure 1). All empty boxes were randomly attributed to one or the other of the symbols (Figure 1). Systematically associating a given symbol to each nest box occupied by a tit pair should thus give, to a newly arrived flycatcher, the artificial information that all tits within a patch have preferred nest boxes with the same symbol. We subsequently monitored nest box choice of newly settling collared flycatcher pairs with respect to the symbol present on the chosen box to determine whether flycatchers copied or rejected the apparent preference of tits. We systematically withdrew symbols from boxes occupied by flycatchers to avoid conspecific information, and in parallel we adjusted the proportion of triangles and circles on remaining empty nest boxes in the patch. We recorded 1497 symbol choices by flycatchers over the 5 years of the experiment, among which 1005 for which both male and female were identified, and thus used in the quantitative genetic analyses. A detailed description of the protocol can be found in Appendix S1.

The symbol associated with tit nests in a given patch was alternated in space among patches so that tit nests were associated 


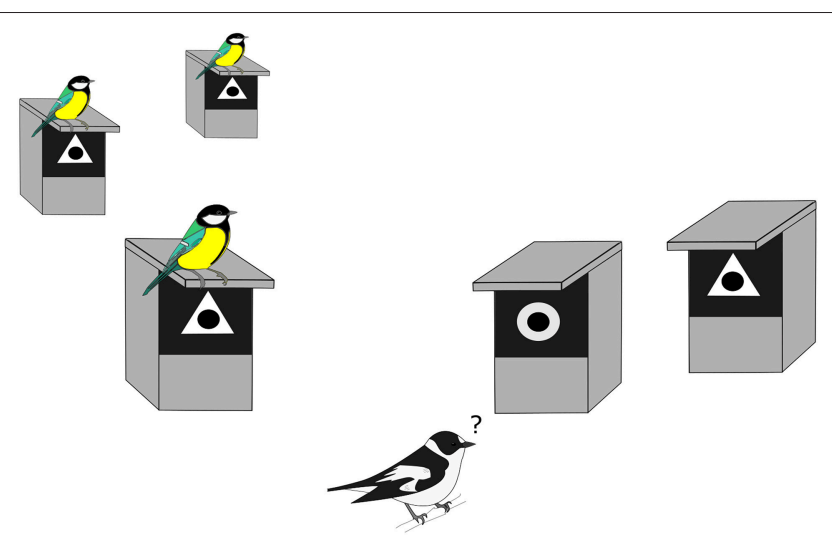

FIGURE 1 | Experimental design used between 2012 and 2016. All nest boxes occupied by great and blue tits were attributed a similar symbol (here a triangle as an example). All other nest boxes available for the flycatchers settlement were attributed either the same symbol as the nest boxes occupied by tits, or the other symbol, in equal proportion. We subsequently monitored the choice of arriving flycatchers (matching or opposing the tit apparent preference). The tit apparent preference for triangle or circle was randomized between forest patches, and systematically changed from one breeding season to the next. The front of all boxes had previously been painted black to increase the contrast with the white symbol.

to a circle in half of the patches and to a triangle in the other half without creating larger-scale apparent preference (see Appendix S1 for the map of the attribution of the symbol associated with tit nests for each patch in 2014). We also switched the symbol associated with tit nests in each patch each year to avoid symbol information reinforcement across years for individuals that returned to the same patch from one year to the next (i.e., philopatric individuals, approximately $70 \%$ of breeding adults in the study population; Doligez et al., 1999).

\section{Statistical Analyses}

We conducted all analyses within the Bayesian framework by using the $\mathrm{R}$ function MCMCglmm (MCMCglmm R package; Hadfield, 2010) in $\mathrm{R}$ version 3.3.2 ( $\mathrm{R}$ Development Core Team, 2011). Our response variable was the probability that flycatchers choose a nest box presenting the same symbol as the one associated to tit nests in the same patch, thereafter called "probability to copy" (binary variable: 1 if choosing a box with the symbol associated with tit nests, i.e., copying the apparent tit preference, and 0 otherwise, i.e., rejecting the apparent tit preference). First, we estimated the repeatability estimate of the probability to copy. The repeatability estimate for a trait provides a maximal value for its heritability (Lynch and Walsh, 1998; but see Dohm, 2002), therefore informing about the possible heritability estimate. However, because of high mortality and breeding dispersal rates in our population, individuals very rarely mate with the same partner over several years (less than $2 \%$ in our sample), and thus we could not estimate the repeatability of the probability to copy at the pair level, but estimated it first only at the individual level. Second, we used a quantitative genetic mixed effects model ("animal model"; Kruuk, 2004; Charmantier et al., 2014) to estimate simultaneously the importance of overall experience (age, familiarity with the environment, and previous experience with the experimental design) on, and quantitative genetic parameters of, the probability to copy at the pair level. Third, we restricted the data to individuals that made multiple nest box choices over the course of the experiment, and explored whether subsequent choices (i.e., excluding the first choice of each individual) depended on personal information previously acquired with respect to the symbols.

\section{Repeatability at the Individual Level}

We estimated individual repeatability in the probability to copy by fitting two binomial generalized linear mixedeffects models (one for males and one for females to avoid pseudoreplication of nest box choice) with the probit link function, including only individual identity as a random effect, and no fixed effect. Repeatability was estimated as the ratio between the individual variance and the total variance plus 1 for the probit link function (Nakagawa and Schielzeth, 2010). Using a similar approach, we also estimated individual repeatability in the probability to choose a specific symbol (either circle or triangle), to test for a potential innate preference for a natural round shape (Forsman et al., 2014).

\section{Animal Model at the Pair Level: Specification and Variance Partitioning}

We used an animal model at the pair level to separate different sources of phenotypic variance in the probability of flycatchers to copy. Animal models allow controlling for fixed effects while partitioning the total phenotypic variance into genetic and nongenetic components by considering all relatedness links between individuals obtained from the pedigree (Wilson et al., 2010). The presence of fixed effects in animal models may increase heritability estimates in particular by decreasing the residual variance (reviewed in Wilson, 2008). We found no quantitative change in variance component estimates between models without and with selected fixed effects (results not shown).

We included in our animal model different fixed effects that may have affected nest box choice with respect to symbols in flycatchers (Table 1). First, because of higher familiarity with their environment (Pärt, 1995), philopatric adults (i.e., individuals that bred in the same patch the previous year) may rely less on social information for habitat quality assessment than newly arrived individuals in the patch, including both young individuals and immigrant adults (Kivelä et al., 2014). Indeed, newly arrived individuals lack personal breeding information on the local patch (i.e., here, information gained through their own breeding experience; Danchin et al., 2004; Dall, 2005). Young, less competitive individuals can also be expected to rely differently on social information for breeding decisions (Doligez et al., 2004a). Therefore, we included in the model a sex-specific three-class status variable to account for the individual's expected level of breeding experience in the patch (Kivelä et al., 2014): (i) yearlings, (ii) older (2 years or older) immigrant individuals, and (iii) older philopatric individuals. Immigrants in a patch were all individuals new to this patch, i.e., comprised both previously 
TABLE 1 | Summary of the fixed effects included in the full animal model fitting the probability to copy tit preference.

\begin{tabular}{|c|c|c|}
\hline Variable & $\begin{array}{l}\text { Number of } \\
\text { levels or range }\end{array}$ & Definition \\
\hline \multicolumn{3}{|c|}{ CATEGORICAL FIXED EFFECTS } \\
\hline Symbol & circle, triangle & Symbol chosen: circle or triangle \\
\hline Pair.symbol.exp & $\begin{array}{l}\text { experienced, } \\
\text { mixed, naive }\end{array}$ & $\begin{array}{l}\text { Whether both pair members } \\
\text { experienced the symbol choice the year } \\
\text { before, none of them, or only one of } \\
\text { them }\end{array}$ \\
\hline Status o & $Y, I, P$ & $\begin{array}{l}\text { Female age and dispersal status: } \\
\text { yearling, older immigrant, or older } \\
\text { philopatric }\end{array}$ \\
\hline Status o & $Y, I, P$ & $\begin{array}{l}\text { Male age and dispersal status: yearling, } \\
\text { older immigrant, or older philopatric }\end{array}$ \\
\hline Flycatcher[y-1] & yes, no & $\begin{array}{l}\text { Presence or absence of a flycatcher } \\
\text { pair breeding in the same nest box the } \\
\text { year before }\end{array}$ \\
\hline \multicolumn{3}{|c|}{ CONTINUOUS FIXED EFFECTS } \\
\hline Day & {$[28 ; 67]$} & $\begin{array}{l}\text { Day of choice, counted from the 1st of } \\
\text { April }\end{array}$ \\
\hline Day $^{2}$ & {$[784 ; 4489]$} & Square the day of choice \\
\hline Dev.symbol & {$[-0.25 ; 0.50]$} & $\begin{array}{l}\mathrm{Nb} \text { of empty boxes with the tit symbol / } \\
\text { Total nb of empty boxes - } 0.50 \text {, on the } \\
\text { day of choice }\end{array}$ \\
\hline Prop.tit & {$[0.03 ; 0.73]$} & $\begin{array}{l}\mathrm{Nb} \text { of tit breeding in the patch on the } \\
\text { day of choice / Total nb of boxes in the } \\
\text { patch }\end{array}$ \\
\hline Prop.flycatcher & {$[0.00 ; 1.00]$} & $\begin{array}{l}\mathrm{Nb} \text { of boxes with the tit symbol } \\
\text { occupied by flycatcher / } \mathrm{Nb} \text { of boxes } \\
\text { with any symbol occupied by flycatcher, } \\
\text { before the day of choice }\end{array}$ \\
\hline
\end{tabular}

unringed adults and dispersers (i.e., individuals that changed breeding patch between years). Second, individuals that were involved in the experiment for several years and made a symbol choice prior to the current choice may be expected to rely on their past experience with symbols and therefore be less likely to copy. Therefore, we included in the model a fixed effect to account for pair members' previous experience with symbols. Preliminary analyses revealed no interaction between the female and male previous experience with symbols on the probability to copy. Therefore, we implemented a joint three-level variable: (i) both pair members were naive to the symbol experiment, (ii) both had already experienced the symbol experiment, and (iii) one pair member was naive and the other one experienced, irrespective of their sex. Separating the latter "mixed" pairs according to the sex of the naive individual did not qualitatively change the results (results not shown).

In addition to factors related to individuals' overall experience, we included as fixed effects in the model (i) the symbol type (triangle or circle) chosen by the pair to control for a potential innate symbol preference; (ii) the date of nest box choice (continuous variable, $1=1$ st of April) and its square value, because late birds tended to copy more in previous experiments, probably as a result of a lack of time to collect personal information (Seppänen and Forsman, 2007), and this effect may be non-linear; (iii) whether or not a flycatcher pair bred in the chosen nest box the year before (binary variable), because collared flycatchers are more likely to select nest boxes occupied by conspecifics in the previous year (Kivelä et al., 2014); (iv) the proportion of nest boxes occupied by tits on the day of choice out of the total number of boxes per patch, because information strength is likely to depend on the proportion of demonstrators in the patch (here tit pairs). Furthermore, the proportion of empty nest boxes with each symbol in each patch was not always exactly equal; this was particularly noticeable when the number of empty boxes was small (i.e., in the smallest patches toward the end of the settlement period). Therefore, we tested whether the probability to copy the apparent symbol preference of tits differed from random by adding the deviation from 0.5 of the proportion of the symbol associated to tit nests on empty boxes (i.e., [number of empty boxes presenting the symbol associated with tits on the day of choice]/[total number of empty boxes in the patch on the day of choice] -0.5 ) as a covariate in the model. The time needed to withdraw symbol on boxes newly occupied by flycatchers could also vary because it was not always easy to classify a small amount of nest material as a proper start of nest (in which case the symbol could be withdrawn only when the nest reached a later stage) and also because the speed of nest building varies between birds. To control for the resulting variation in individuals' exposure to conspecific information among newly settled flycatchers, we added as a covariate the ratio of nest boxes occupied by conspecifics (i.e., with at least $0.5 \mathrm{~cm}$ of dry grass) that presented the symbol associated to tit nests over all boxes occupied by flycatchers with either symbol in the same patch 2 days before settlement (i.e., on the last check before the settlement was detected).

Regarding the quantitative genetic estimates, the animal model disentangled sex-specific additive and non-additive genetic effects to estimate as accurately as possible the additive genetic variance $\mathrm{V}_{\mathrm{A}}$. The model therefore included sex-specific dominance and maternal effects (McAdam et al., 2002; Wilson et al., 2010; Wolak and Keller, 2014) as random effects. Because we had several nest box choices for a fraction of individuals over the years, we accounted for a permanent environment effect by including the identities of the male and female as random effects. Because of the low inter-annual pair fidelity in our population (see above), we did not control for pair identity in our model. Finally, we also included year and nest box identity as random effects to account for spatio-temporal environmental variability. Including the patch instead of the nest box or including the year as a fixed effect instead of a random effect did not qualitatively change the results (results not detailed). Model specification is detailed in Appendix S2.

We partitioned the phenotypic variance as follows (Equation 1):

$$
\begin{aligned}
V_{P}= & V_{A q}+V_{A \sigma^{\top}}+2 \operatorname{Cov}_{A \text { q丁 }} \times 2 k_{\text {mean }}+V_{D Q}+V_{D 0^{\top}}+V_{M Q} \\
& +V_{M \sigma^{\top}}+V_{P E q}+V_{P E q}+V_{Y}+V_{N}+V_{R}
\end{aligned}
$$

(Bijma et al., 2007a,b) where $V_{A}$ and $V_{A \sigma^{7}}$ are sex-specific additive genetic variances, $\operatorname{Cov}_{A Q \sigma^{7}}$ is the cross-sex additive genetic covariance, $2 k_{\text {mean }}$ is the mean female-male relatedness 
across breeding pairs, estimated from the pedigree (twice the mean pairwise coefficient of kinship; Bijma et al., 2007a,b; Bouwman et al., 2010; Germain et al., 2016); $V_{D \text { q }}$ and $V_{D 0^{7}}$ are the sex-specific dominance variances; $V_{M}$ and $V_{M \sigma^{\pi}}$ are the sex-specific maternal identity variances; $V_{P E}$ and $V_{P E O^{T}}$ are the sex-specific variances associated to the permanent environment effect (individual identities); $V_{Y}$ is the variance associated to the year; $V_{N}$ is the variance associated to the nest box; and $V_{R}$ is the residual variance, which has to be fixed in the case of a binomial response variable (see Nakagawa and Schielzeth, 2010).

Sex-specific narrow-sense heritability estimates $h_{\%}^{2}$ and $h_{\sigma^{7}}^{2}$ were computed as the ratio of the sex-specific additive genetic variance over the total phenotypic variance $V_{P}+1$ (the addition of 1 accounting for the probit link function; see Nakagawa and Schielzeth, 2010). The proportion of phenotypic variance explained by the total additive genetic variance, $T^{2}$, was computed as the ratio of the total additive genetic variance to $V_{P}$ + 1 (Equation 2; Bijma et al., 2007a,b; Bouwman et al., 2010) as follows:

$$
T^{2}=\frac{V_{A}}{V_{P}+1}=\frac{V_{A} \varphi+V_{A} \sigma^{\top}+2 \operatorname{Cov}_{A} \sigma^{\top}}{V_{P}+1}
$$

\section{Probability to Copy in Subsequent Years}

We explored whether the individual probability to copy was affected by previous personal information about symbols at the individual (and not pair) level by restricting the data to the 2nd and subsequent (up to 5 th) individual choices ( $N=354$ choices made by 276 females, and 243 choices made by 187 males). We fitted separate models for males and females to avoid pseudoreplication in nest choice and included as fixed effects: whether the individual copied the year before (copied vs. rejected), the age the year before (yearling vs. older), the individual's reproductive success the year before (success vs. failure; considering the continuous variable of the number of fledged youngs instead gave similar results) and its interaction with the past copying behavior. We also controlled for the deviation to the equal proportion of symbols on the day of choice (Dev.symbol, see Table 1) and whether the individual was tested for the 2 nd, $3 \mathrm{rd}$, 4 th, or 5 th time. Philopatric individuals always experienced opposite tit preferences in successive years (see section Materials and Methods) but immigrants (in this case, all dispersers with known previous breeding patch) may experience either the same or the opposite symbol preference depending on their previous breeding patch. However, because breeding dispersal is very low in flycatcher males, only 4 male choices out of 243 were made while exposed to the same tit preference in two successive years; therefore, we tested this in females only. We included as fixed effects the dispersal status (philopatric vs. immigrant) and the variation experienced in the symbol associated to tits between successive years (i.e., apparent preference for the same vs. the opposite symbol), along with its interaction with past copying behavior, in the female model only. As random effect, we included the year, the forest patch, and the individual identity (i.e., no genetic random effects) in both models.

\section{Implementation of Models}

We fitted our binary response variable (copy vs. reject) with the ordinal family. We used parameter expanded $\chi^{2}$ distributions with 1 degree of freedom for the prior distributions of our variances (de Villemereuil et al., 2013; Hadfield, 2014). We fixed the residual variance to 10 here instead of the value of 1 usually used for a binary response variable to improve the mixing of the Markov chain Monte-Carlo (MCMC) chains (Hadfield, 2014). Indeed, preliminary analyses showed that estimated variances were expected to be small here. For the fixed effects, we used the classical diffused centered normal distribution with large variance ( $V=10^{8}$; Hadfield, 2014). Heritability estimates are given on the liability scale (i.e., taking into account the variance associated to the link function; see Nakagawa and Schielzeth, 2010; de Villemereuil et al., 2013, 2016). All other posterior modes and 95\% credible intervals (CI) presented are given on the latent (link) scale in the text and the tables, and on the original scale in the figures.

For the implementation of animal models, the social pedigree was prepared using the function fixPedigree (pedantics R package; Morrissey and Wilson, 2010). As in many other passerine populations, $15 \%$ of all nestlings are extra-pair (Sheldon and Ellegren, 1999). Such a relatively low extra-pair paternity rate should allow us to estimate quantitative genetic effects accurately enough from social pedigree (Charmantier and Réale, 2005). The number of individuals was large in our quantitative genetic analyses (from 141 up to 311 complete breeding pairs per year over 5 years), with a pedigree depth of 15 years (Quinn et al., 2006). To optimize model computation, the pedigree was pruned using function prunePed from the MCMCglmm R package (Hadfield, 2010) and the dominance genetic relatedness matrix was derived from this pruned pedigree using function makeD (nadiv R package; Wolak, 2012). The pruned pedigree comprised 2623 individuals with a mean female-male relatedness across breeding pairs $2 k_{\text {mean }}$ of 0.001 (see Appendix S3 for details on the pedigree characteristics).

We ran the MCMC chains for 600,000 iterations, using a burn-in period of 10,000 iterations and a thinning interval of 150 (except mentioned otherwise in some sensitivity analyses, see Appendix S4). Our effective sample size was approximately 3,000 for each parameter, autocorrelations of the posterior samples being always below 0.1 . The convergence of the MCMC chains was assessed visually and by using the Heidelberg stationary test on the random factors (heidel.diag function, MCMCglmm R package; Hadfield, 2010). We removed the genetic correlation effect from the full model as its Heidelberg stationary and half-width tests showed conflicting outcomes despite a high number of retained iterations, suggesting a variance of zero. We then selected fixed effects by hierarchically removing the effects whose $95 \%$ CI encompassed zero, starting with the effects with a posterior mode closer to zero. Because this stepwise method may increase the risk of type-I error (Mundry and Nunn, 2009; Forstmeier et al, 2017), we compared the 95\% CI in the selected fixed structure to those obtained from the full models, but retained estimates from the selected models. Removing the genetic correlation effect after selecting the fixed effects did not change the results (results not detailed, but see Appendix S5 for 
the full model output). Finally, for the animal model, we checked the sensitivity of the results to (1) the prior chosen, (2) the years included in the dataset, (3) the value chosen for $V_{R}$, and (4) the presence of the dominance or maternal identity effects (see Appendix S4).

\section{RESULTS}

The probability to copy was significantly higher than random (i.e., copying tit preference) in 2012 (the only year where all individuals were naive with respect to the symbols; $\chi_{1}^{2}=6.28$, $p$-value $=0.012$, Table 2 ). The probability to copy did not differ from random in 2014, 2015, or 2016 (Table 2). When restricting the data to naive pairs over the years, the probability to copy was significantly lower than random in 2013 (i.e. rejecting tit preference; $\chi_{1}^{2}=4.36, p$-value $=0.037$, Table 2 ). Overall, the proportion of nest boxes chosen that presented the symbol associated to tit nests was not different from random $(50.6 \%$, $\chi_{1}^{2}=0.19, p$-value $=0.660$, Table 2 ), which was likely due to opposing patterns of copying in 2012 and 2013 combined with the absence of copying on average from 2014 onwards. Flycatchers arrived later on average in 2013 and 2015 compared to other years (Table 2). Nevertheless, the day of choice $(95 \%$ $\mathrm{CI}=[-0.54 ; 0.53])$ did not explain the probability to copy (Appendix S5). Similarly, the proportion of boxes occupied by tits on the day of choice was greater in 2012, but this variable did not affect the probability to copy $(95 \% \mathrm{CI}=[-3.77$; 3.51], Appendix S5). As could be expected, when a symbol was overrepresented on the empty boxes in a given patch, the probability to choose a box with this symbol was higher than random $(95 \% \mathrm{CI}=[3.97 ; 20.26]$, Table 3$)$.

\section{Repeatability Estimates}

Repeatability estimates for the probability to copy, estimated as the proportion of variance attributable to individual identity (compared to residual variance $\mathrm{V}_{\mathrm{R}}+1$; Nakagawa and Schielzeth, 2010) did not differ from zero for either sex (95\% CI $=[0 ; 0.087]$ for females, $N=1368$; [0;0.086] for males, $N=1014$ ). Similarly, repeatability estimates for the probability to settle in a box with a circle (i.e., "prefer" a circle over a triangle) did not differ from zero for either sex $(95 \% \mathrm{CI}=[0 ; 0.094]$ for females, $[0 ; 0.108]$ for males).

\section{Age, Experience, and Environmental Effects on the Probability to Copy}

Based on the animal model output, pairs including a yearling male were more likely to copy compared to pairs including an older immigrant male (56.0\% of copying over the years, against $47.3 \%$ for pairs with an old immigrant male; $95 \% \mathrm{CI}=[0.125$; 1.698], Tables 2, 3, Figure 2). Pair experience with symbols, defined as whether both or one partner was naive or had experience with symbol choice had no effect on the probability to copy, even though we got a slight trend for mixed pair to reject tit preference (95\% CI $=[-2.089 ; 0.185]$, Appendix S5). The deviation to the proportion of empty boxes with the symbol associated with the tit preference had the strongest effect on the probability to copy (Table 3), but the distribution of this deviation was highly condensed around zero (Figure 2). The day of choice, its quadratic effect, the symbol chosen (triangle or circle), the proportion of tutors in the patch and the proportion of informative flycatchers did not explain the probability to copy (Appendix S5).

\section{Quantitative Genetics of the Probability to Copy}

There was no cross-sex additive genetic covariance in the probability to copy $(95 \% \mathrm{CI}=[-0.017 ; 0.018]$ in the full model). Therefore, we removed this covariance from our model. The proportion of phenotypic variance explained by the total additive genetic effects, $T^{2}$, was thus calculated as the sum

TABLE 2 | Annual variations in the copying behavior, number of choices, and flycatcher and great tit phenology.

\begin{tabular}{|c|c|c|c|c|c|c|}
\hline & 2012 & 2013 & 2014 & 2015 & 2016 & Overall \\
\hline \multicolumn{7}{|l|}{ COPYING IN \% (N) } \\
\hline All pairs & $59.2(184)$ & 46.8 (378) & $51.8(423)$ & 49.7 (312) & $48.5(200)$ & $50.6(1497)$ \\
\hline Pairs naive to the symbols & $59.9(137)$ & $41.9(167)$ & $57.6(144)$ & $49.3(69)$ & $48.3(58)$ & $51.7(575)$ \\
\hline Pairs with a yearling male & $66.7(30)$ & $52.2(69)$ & $61.8(68)$ & $46.4(28)$ & $47.6(21)$ & $56.0(216)$ \\
\hline Pairs with an older male & 57.7 (116) & 38.6 (166) & $50.0(230)$ & $48.1(156)$ & $48.5(130)$ & $48.1(798)$ \\
\hline \multicolumn{7}{|l|}{ FLYCATCHER PHENOLOGY } \\
\hline Day of choice & $39.5 \pm 3.9$ & $42.2 \pm 3.9$ & $39.9 \pm 5.7$ & $45.9 \pm 6.1$ & $39.3 \pm 5.3$ & \\
\hline Laying date & $47.8 \pm 3.1$ & $50.8 \pm 2.7$ & $48.8 \pm 3.3$ & $53.1 \pm 5.0$ & $45.8 \pm 4.2$ & \\
\hline \multicolumn{7}{|l|}{ TIT PHENOLOGY } \\
\hline Laying date & $29.8 \pm 4.9$ & $42.3 \pm 3.9$ & $29.6 \pm 5.4$ & $31.6 \pm 4.5$ & $26.6 \pm 6.9$ & \\
\hline Prop.tit (\%) & 49.1 & 27.1 & 35.2 & 32.2 & 41.6 & \\
\hline $\begin{array}{l}\text { Number of days between flycatchers } \\
\text { and tit laying dates }\end{array}$ & 18.0 & 8.5 & 19.2 & 21.5 & 19.2 & \\
\hline
\end{tabular}

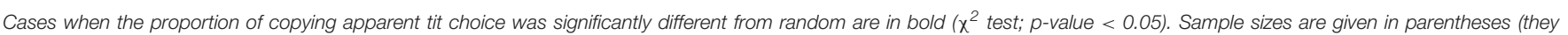

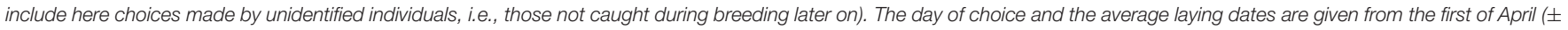
$S D)$. 
TABLE 3 | Posterior modes and credible intervals of the final animal model fitting the probability to copy the tit preference.

\begin{tabular}{|c|c|c|c|}
\hline & Posterior mode & CI (95\%) & $\begin{array}{c}\text { Effective } \\
\text { sample size }\end{array}$ \\
\hline \multicolumn{4}{|l|}{ FIXED EFFECTS } \\
\hline Intercept & -0.345 & {$[-1.080 ; 0.558]$} & 3,934 \\
\hline \multicolumn{4}{|l|}{ Status o } \\
\hline Older philopatric & 0.202 & {$[-0.493 ; 0.788]$} & 3,934 \\
\hline Yearling & 0.964 & {$[0.125 ; 1.698]$} & 3,593 \\
\hline Dev.symbol & 12.907 & [3.971; 20.260] & 3,726 \\
\hline \multicolumn{4}{|c|}{ RANDOM EFFECTS } \\
\hline $\mathrm{V}_{\mathrm{A}+}$ & 0.004 & {$[0 ; 1.010]$} & 3,934 \\
\hline$V_{\mathrm{AO}^{x}}$ & 0.008 & [0; 1.229] & 3,934 \\
\hline$V_{D_{q}}$ & 0.007 & {$[0 ; 1.219]$} & 3,934 \\
\hline$V_{D^{7}}$ & 0.007 & {$[0 ; 1.256]$} & 3,934 \\
\hline $\mathrm{V}_{\mathrm{M} \varphi}$ & 0.015 & {$[0 ; 2.102]$} & 3,934 \\
\hline $\mathrm{V}_{\mathrm{Mo}}$ & 0.010 & {$[0 ; 2.563]$} & 3,687 \\
\hline$V_{\text {PEO }}$ & 0.003 & {$[0 ; 1.355]$} & 3,934 \\
\hline$V_{\text {PEO' }}$ & 0.004 & {$[0 ; 1.180]$} & 3,934 \\
\hline$V_{Y}$ & 0.177 & {$[0 ; 1.589]$} & 3,659 \\
\hline$V_{N}$ & 0.009 & {$[0 ; 1.710]$} & 3,349 \\
\hline$V_{R}$ & 10.000 & {$[10 ; 10]$} & 0 \\
\hline \multicolumn{4}{|c|}{ DERIVED ESTIMATES } \\
\hline $\mathrm{h}_{\mathrm{q}}^{2}$ & 0.0005 & {$[0 ; 0.064]$} & 3,934 \\
\hline$h_{\sigma^{7}}^{2}$ & 0.0002 & {$[0 ; 0.077]$} & 3,934 \\
\hline $\mathrm{T}^{2}$ & 0.0013 & {$[0 ; 0.106]$} & 3,934 \\
\hline
\end{tabular}

Estimates for the selected fixed and random effects are given on the latent scale with the residual variance $V_{R}$ set to 10 . See Table 1 for a detailed description of the fixed effects. For the male categorical status variable (Status $\sigma^{\top}$ ), older immigrant males are considered as the group of reference.

$V_{A}$ a and $V_{A 0^{x}}$, sex-specific additive genetic variances; $V_{D o}$ and $V_{D 0^{7}}$, sex-specific dominance variances; $V_{M}$ and $V_{M 0^{x}}$, sex-specific maternal identity variances; $V_{P E Q}$ and $V_{P E \sigma^{2}}$, sex-specific variances associated to the permanent environment effect (individual identity); $V_{Y}$, variance associated to the year; $V_{N}$, variance associated to the nest box; $V_{R}$, residual variance. $h_{O}^{2}$ and $h^{2}$, sex-specific narrow-sense heritability estimates; $T^{2}$, proportion of phenotypic variance explained by the total sex-specific additive genetic effects.

of both sex-specific heritabilities. The posterior modes of all additive genetic variances and heritability estimates were below 0.01 (Table 3). The posterior distributions of all variances and heritability estimates were condensed close to 0 (Appendix S4). The above figures were obtained when using $V_{R}=10$ but when increasing $V_{R}$, the posterior distributions for the sex-specific heritabilities and $T^{2}$ shifted even further toward 0 (Appendix S4). Overall, the results strongly suggest that the additive genetic variance components (as well as non-genetic components) and heritability estimates were not different from 0 .

\section{Probability to Copy in Subsequent Years}

In males, none of the variables explained the probability to copy the subsequent year (Table 4). Females tended to reject if they had copied in the previous year, but only if they were again exposed to the same apparent tit preference as in the previous year $(89.6 \%$ out of 22 female choices copied on average, Figure 3, Table 4). On the contrary, when females were exposed to the opposite apparent tit preference, their copying behavior did not depend on whether they had copied or not in the previous year (Figure 3, Table 4).

\section{DISCUSSION}

In this study, we investigated the influence of genotypic and phenotypic variation on social information use for habitat selection by experimentally manipulating a source of heterospecific (tit) social information in a wild flycatcher population. We estimated (1) repeatability in information use for nest site selection (at the individual level) as well as (2) the effect of individual overall experience as measured by age, familiarity with the environment, previous experience with the experimental design, and previous breeding success, and (3) female and male direct and indirect genetic effects on information use for the joint nest site selection (at the pair level). The probability to copy apparent tit nest site choices showed variation among years: flycatchers tended to copy apparent tit choices in the first year of the experiment (2012) but reject it the following year. Flycatcher pairs where the male was a yearling were more likely to copy the apparent tit choice than pairs with an older immigrant male (but not pairs with an older philopatric male), indirectly suggesting a sex-specific difference in social information use in nest site selection. Individual repeatability in the probability to copy apparent tit choices, as well as the sex-specific estimates of additive genetic variance and heritability, were null. Thus direct and indirect genetic effects explained no part of the variance in the probability to copy apparent tit choices. These results are in line with large environmental variances observed in other behavioral studies (Stirling et al., 2002; Bell et al., 2009; Dochtermann et al., 2015) and potentially reflect that social information use in nest site selection is most importantly affected by environmental factors, including the availability and reliability of the information obtained from tits. The ability to perceive and use social information may, however, have a genetic basis and respond to selection, even though we did not find genetic variation in the use of a specific, experimentally provided, source of social information.

\section{The Role of Experience in Social Information Use}

As expected, individual overall experience partly affected the probability to copy tit choices in this study. Regarding the effect of age and familiarity with the environment, a previous study in the same population showed that pairs where both partners were old and philopatric were more likely to settle in nest boxes occupied by conspecifics in the previous year, than pairs where at least one member was a yearling or an immigrant (Kivelä et al., 2014). Because this source of social information (i.e., conspecific presence in the previous year) was probably not (or little) available for yearlings and immigrants, this suggests that the use of social information depends on its availability to individuals. Here, the higher probability to copy tit choices in pairs with yearling males compared to pairs with older immigrant males suggests that, in collared flycatchers, this heterospecific social information in the current year may be used for nest 


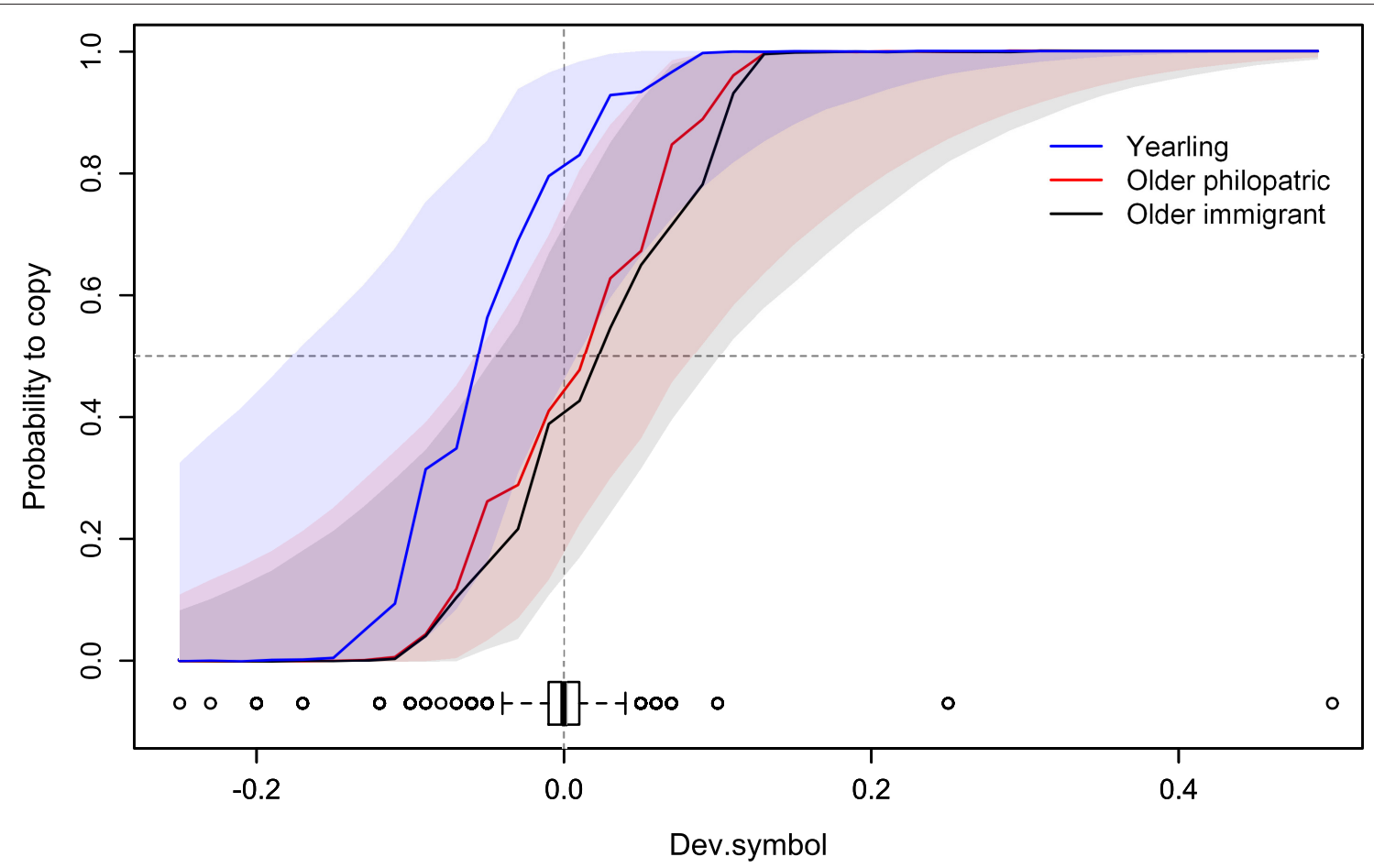

FIGURE 2 | Relationship between the probability to copy and the deviation to an equal proportion of symbols on empty boxes (Dev.symbol, see Table 1) for the different male age and dispersal status (yearling/older immigrant/older philopatric). Positive values of Dev.symbol indicate a prevalence of empty nest boxes with the same symbol as the tit apparent preference. The posterior modes (solid lines) and their 95\% Credible Intervals (shades) are given on the original scale, for pairs with a yearling male (in blue), an older philopatric male (in red), or an older immigrant male (in black). The vertical dashed line corresponds to an even proportion of triangles and circles on empty boxes on the day of flycatcher choice. The horizontal dashed line corresponds to a random choice (probability $=0.5)$. The boxplot represents the distribution of Dev.symbol. There was no interaction between Dev.symbol and the male experience status.

site selection in particular by late arriving, less competitive individuals (Doligez et al., 2004a). We could not detect a difference in the probability to copy between pairs with a yearling or an older philopatric male, but this might only be due to a lack of power. Indeed, Figure 2 suggests that the probability to copy was similar between pairs with older philopatric and immigrant males. Our results are thus in accordance with previous results on heterospecific nest site copying behavior in collared and pied flycatchers using the same experimental design showing higher probability to copy tit choices for late arriving, thus presumably young individuals (Seppänen and Forsman, 2007). The age-related difference in the probability to copy apparent tit preference for nest site selection suggests that the use of this heterospecific source of information is more advantageous for yearlings. More work would be needed to determine whether this results from their lower level of personal information or from a temporal change in the reliability or value of this information source along the season.

Males may have a preponderant influence on nest site selection, as illustrated by the absence of effect from female age and dispersal status on the joint nest site selection phenotype (Jaakkonen et al., 2013). The low female contribution to the joint phenotype observed here contrasts with another recent experimental study in the pied flycatcher, where only females used tit phenology as a source of social information for breeding site selection (Samplonius and Both, 2017). Even though our study is not directly comparable with that of Samplonius and Both (2017), both report differences between sexes in social information use for breeding site selection, and our results also suggest a differential effect of individual experience as reflected by age and dispersal status between sexes. Such between-sex differences may result from sex-specific information gathering processes (Reed et al., 1999; Doligez et al., 2004b), in relation to sex-specific fitness benefits associated with breeding system and dispersal processes (Greenwood, 1980). In birds, males are expected to benefit from fine-scale knowledge of their environment, which can be achieved by philopatry and finescale prospecting within the natal habitat and allows them to select and defend high-quality territories where to attract females (Greenwood, 1980; Doligez et al., 2004b). Conversely, females benefit from larger-scale knowledge of the environment and thus larger-scale prospecting, leading to longer dispersal distances, allowing them to select the best males or territories (Greenwood, 1980; Arlt and Pärt, 2008). These sex-specific selective pressures acting on the knowledge of the environment and information gathering may translate into the use of different information sources (including social information) between sexes and/or differential use of the same information depending on individual experience, as suggested here. Both our results and previous results (Samplonius and Both, 2017) are coherent with a preponderant use of fine-scale social information by males and large-scale social information by females. 
TABLE 4 | Posterior modes and credible intervals of the model explaining the probability to copy in subsequent years.

\begin{tabular}{|c|c|c|c|c|c|c|}
\hline & \multicolumn{2}{|c|}{ Male full model } & \multicolumn{2}{|c|}{ Female full model } & \multicolumn{2}{|c|}{ Female final model } \\
\hline & Post mode & $\mathrm{Cl}(95 \%)$ & Post mode & Cl (95\%) & Post mode & $\mathrm{Cl}(95 \%)$ \\
\hline \multicolumn{7}{|l|}{ FIXED EFFECTS } \\
\hline Intercept & 1.199 & {$[-2.771 ; 4.463]$} & -3.279 & {$[-6.136 ; 1.015]$} & 0.017 & {$[-1.142 ; 0.778]$} \\
\hline Success y-1 (success) & -0.040 & {$[-3.301 ; 2.695]$} & 1.237 & {$[-0.501 ; 3.993]$} & & \\
\hline Age y-1 (yearling) & 0.472 & {$[-0.891 ; 1.761]$} & 0.548 & {$[-0.465 ; 1.909]$} & & \\
\hline Choice y-1 (copying) & 0.084 & {$[-3.267 ; 3.936]$} & 0.716 & {$[-2.654 ; 2.918]$} & 0.004 & {$[-1.094 ; 1.057]$} \\
\hline Tit preference y-1 (same) & & & 1.890 & {$[-0.841 ; 4.706]$} & 1.538 & {$[-0.103 ; 4.177]$} \\
\hline Dispersal status (philopatric) & & & -0.675 & {$[-2.473 ; 1.083]$} & & \\
\hline Dev.symbol (c.f. Table 1) & 12.322 & {$[-9.912 ; 33.289]$} & 4.776 & {$[-7.827 ; 24.552]$} & & \\
\hline Number of past symbol experience & -0.180 & {$[-1.269 ; 0.771]$} & 0.700 & {$[-0.262 ; 1.588]$} & & \\
\hline Choice: Tit preference y-1 (copying: same) & & & -3.244 & {$[-6.162 ;-0.215]$} & -2.903 & {$[-5.778 ;-0.227]$} \\
\hline Choice: Success y-1 (copying: success) & -0.668 & {$[-4.252 ; 3.329]$} & -0.492 & {$[-3.317 ; 2.374]$} & & \\
\hline \multicolumn{7}{|l|}{ RANDOM EFFECTS } \\
\hline$V_{P E}$ & 0.008 & {$[0 ; 2.006]$} & 0.040 & {$[0 ; 7.454]$} & 0.020 & {$[0 ; 5.337]$} \\
\hline$V_{Y}$ & 0.013 & {$[0 ; 1.226]$} & 0.013 & {$[0 ; 1.327]$} & 0.008 & {$[0 ; 0.959]$} \\
\hline$V_{\text {patch }}$ & 0.009 & {$[0 ; 1.131]$} & 0.010 & {$[0 ; 1.139]$} & 0.003 & {$[0 ; 0.875]$} \\
\hline$V_{R}$ & 10.000 & {$[10 ; 10]$} & 10.000 & {$[10 ; 10]$} & 10.000 & {$[10 ; 10]$} \\
\hline Effective sample size & & $>3,934$ & & $>3,779$ & & $>2,859$ \\
\hline
\end{tabular}

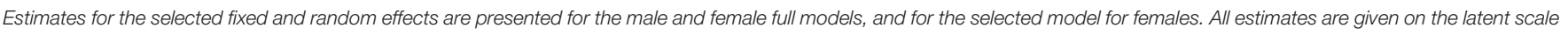

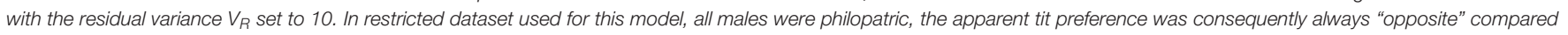
to the previous year. For categorical variables, estimates are given for the category between parentheses, the category of reference being part of the intercept estimate.

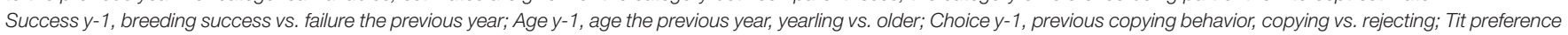

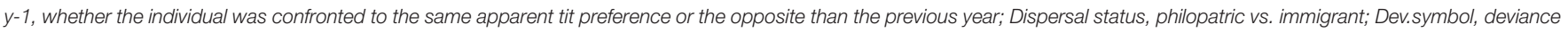

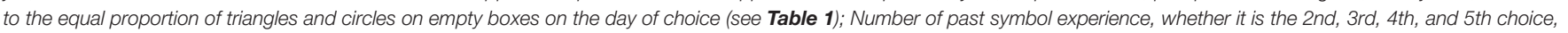

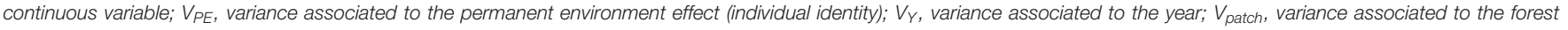
patch; $V_{R}$, residual variance, set to 10 .

Overall, previous pair experience with symbols had no effect on the probability to copy apparent tit choices. Nevertheless, individuals were more likely to copy tit choices in the first year of the experiment, when they were all naive to the experimental set-up. Previous experiments in this system using a similar experimental design have been conducted only for 1 year in most cases, thus including only naive individuals (Seppänen and Forsman, 2007; Seppänen et al., 2011; Jaakkonen et al., 2013). This could explain the contrast between our overall results, including individuals experienced with the symbols, and former studies. However, when excluding the first symbol choice (i.e., by naive individuals), experienced females tended to copy tit choice when they had rejected it the year before and were again exposed to the same apparent tit preference. Those females were all dispersing individuals, but not all dispersers were exposed to the same apparent preference depending on the patch they dispersed to. This switching behavior did not depend on the individual's past reproductive success, even though past success affected dispersal decisions in the same population (Doligez et al., 1999), but at a much larger spatial scale (patch vs. nest site here). Importantly, our experimental set-up de facto disconnected the use of heterospecific social information for nest site selection from its fitness payoffs. This may have led part of the individuals that failed in breeding to learn and use other information sources in subsequent nest-site choices. To what extent such learning processes are under genetic determinism and thus interfere when estimating heritability of information use in wild populations, remains unknown. Specific caution should be taken in this respect when designing long-term experiments where the association between manipulated information and fitness payoff is altered.

\section{High Environmental Variances: The Role of between-Species Synchrony}

Most of the variance in the use of apparent tit nest site choice was here due to environmental factors. One of the main factors that may affect the probability for flycatchers to copy apparent heterospecific (tit) nest site choice was the temporal delay between tit reproduction and flycatcher arrival. The usual time interval between average tit and flycatcher laying date is $2-3$ weeks on Gotland but it may strongly vary among years (Table 2). When tit reproduction is delayed, the number of tit demonstrators upon flycatcher arrival from wintering grounds, and thus the strength and possibly the reliability of heterospecific information, may decrease, due in particular to environmental stochasticity (see also Parejo, 2016 for a discussion on information mismatching). Interestingly, female pied flycatchers have been shown to prefer settling in forest patches where tit phenology is early (Samplonius and Both, 2017). Here, we found no effect of the date of choice by flycatchers or the proportion of nest boxes occupied by tit pairs in the patch, which suggests that the number of tit demonstrators may 


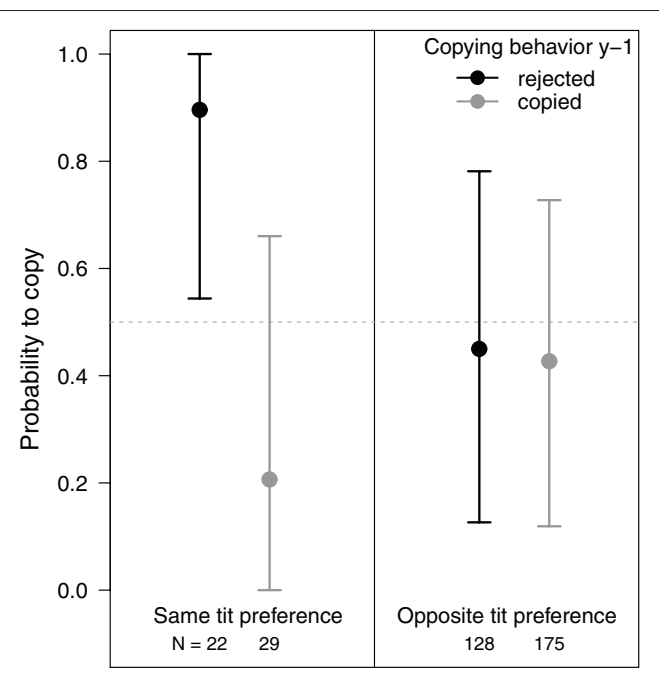

FIGURE 3 | Female probability to copy in subsequent nest site choices, given previous copying behavior and the difference in exposure to the apparent tit preference compared to the previous year. Females were either exposed to the same (Left) or opposite (Right) apparent tit preference than the year before. Females that rejected (did not copy) the tit preference the year before are represented in black, and females that copied are represented in light gray. Posterior means and $95 \% \mathrm{Cl}$ are given on the original scale. The horizontal dashed line corresponds to a random choice (probability $=0.5$ ). Sample sizes are given at the bottom of each panel. Sample sizes are higher for females exposed to the opposite tit preference because this situation corresponds to both the philopatric females and the females that dispersed to a patch with the opposite symbol.

not have strongly affected inter-individual variation in copying behavior here (Jaakkonen et al., 2013). Nevertheless, betweenspecies temporal delay may explain variation in copying behavior at the inter- rather than intra-annual scale. In 2013, tit pairs settled much later than in other years, leading to the lowest proportion of tit demonstrators settled (Table 2), but also to apparently small tit clutches upon flycatcher's arrival, because tits were still settling or laying. This could explain why flycatchers, especially pairs with old males that arrive first, did not just choose at random but actually rejected tit choices in 2013, in line with previous results (Seppänen et al., 2011; Loukola et al., 2013). In contrast, 2012 was the year with the highest proportion of tit demonstrators upon flycatcher settlement. This could contribute to explain the higher probability to copy in 2012 compared to other experimental years.

The high residual variance in the probability to copy may also partly be due to the experimental design used here. In many of the former experiments based on symbol choice in the tit-flycatcher system, each nest box was paired with another one at a distance of ca. $2 \mathrm{~m}$ and the two boxes received different symbols. This allowed settling flycatchers to choose between symbols independently from other characteristics of the microhabitat (Seppänen and Forsman, 2007; Seppänen et al., 2011; Loukola et al., 2012; Forsman et al., 2014). Here, we used a single-box design to be able to conduct our experiment over large spatial and temporal scales, but the choice of a nest box could in this case be associated not only with the symbol but also with other microhabitat characteristics around the box. Consistent differences in preference for nest boxes (measured by the probability and date of occupancy) over years have been found in this population, and they were suggested to relate to local microhabitat quality (Pärt, 1995). Here, by including nest box as a random factor, we aimed at controlling for such small-scale habitat characteristics. Nevertheless, microhabitat quality around a box (including the inter- and intra-specific social neighborhood) is likely to remain an important source of residual variance in the probability to copy. Other environmental factors could also participate in the high residual variance but they remain to be identified.

\section{No Additive Genetic Variance}

We found no additive genetic variance for the probability to use our experimentally provided heterospecific social information for nest site choice. Other quantitative genetic studies also found low or null estimates of additive genetic variance in joint breeding phenotypes. For example, considering sex-specific additive genetic variances as we did here, breeding time was found not to be heritable in female red-billed gulls (Larus novaehollandiae scopulinus, Teplitsky et al., 2010) or in male blue tits (Caro et al., 2009). From an evolutionary point of view, low or null estimates of additive genetic variances may reflect either a high degree of phenotypic plasticity, an erosion of additive genetic variance through selection, and/or an absence of genetic basis of social information use. In the context of breeding site selection, social information use is expected to be highly beneficial, because acquiring the same information by direct sampling of the environment can entail high costs in terms of time, energy, and missed opportunities, especially in short-lived species (Doligez and Boulinier, 2008), and the use of social information for breeding site selection has indeed been experimentally demonstrated in different species (Doligez et al., 2002; Boulinier et al., 2008). In the flycatchers-tits system, pied flycatchers have been shown to gain fitness benefits when breeding in proximity to great tits (by achieving earlier breeding, and heavier and larger broods; Forsman et al., 2002). Flycatchers have also been observed actively prospecting inside great tit nest boxes (Forsman and Thomson, 2008; Forsman et al., in press) despite a high risk of being killed (Merilä and Wiggins, 1995). Altogether, these results suggest strong benefits of heterospecific information use that should exceed the costs of interspecific competition and information acquisition. Thus, heterospecific social information use for nest site selection may often be adaptive and should be favored but whether individuals actually use it in the context of our study (i.e., copying vs. rejecting tit choice) seemed highly plastic, which could be related to spatiotemporal changes in the quality (i.e., availability and reliability) of information.

Our results are in line with the idea that stochastic environmental variation should strongly affect social information use strategies by shaping the quality of information (e.g., Doligez et al., 2003). In our study, the quality of heterospecific information could have been in particular dependent on the 
synchrony between the information provider and user. Its use therefore appeared plastic and not genetically inherited. However, what could be genetically based and should be under strong selective pressures could be the ability to use the specific sources of information (among social, personal, and environmental cues) that provide the highest quality information depending on spatio-temporally changing environmental conditions rather than the use of a given source of information itself. Such adjustment of information use could in particular result from learning. While learning has been found to be heritable in captive populations (e.g., Mery and Kawecki, 2002), no estimation of the heritability of learning and its genetic covariance with social information use is available in the wild so far. More generally, estimating the genetic basis of optimally adjusting social information use would require testing the use of different information sources in different environmental conditions. For example, both social information (e.g., the tit apparent preference for an artificial nest site feature) and the quality of information providers (e.g., tit clutch size) could be manipulated simultaneously in a crossed design (see Forsman and Seppänen, 2011) to explore the phenotypic and genetic contribution to the probability to make the apparently optimal decision (here, copying the choice of high quality individuals with large clutches, and rejecting the choice of low quality individuals with small clutches). Such experiment would have to be conducted over many years to account for possibly strong environmental variability, as observed here. Thus, testing this hypothesis in the wild remains a challenging task and more work on the quantitative genetics of social information use is needed to understand its evolution.

\section{ETHICS STATEMENT}

This study was carried out in accordance with the Swedish law regarding experiments on animals, under licenses of the Natural History Museum of Stockholm for the capture and

\section{REFERENCES}

Alatalo, R. V., Lundberg, A., and Björklund, M. (1982). Can the song of male birds attract other males? An experiment with the pied flycatcher Ficedula hypoleuca. Bird Behav. 4, 42-45. doi: 10.3727/0156138827915 60576

Arlt, D., and Pärt, T. (2008). Sex-biased dispersal: a result of a sex difference in breeding site availability. Am. Nat. 171, 844-850. doi: 10.1086/587521

Arnqvist, G., and Rowe, L. (2005). Sexual Conflict. Princeton, MJ: Princeton Univ. Press.

Avarguès-Weber, A., Dawson, E. H., and Chittka, L. (2013). Mechanisms of social learning across species boundaries. J. Zool. 290, 1-11. doi: 10.1111/jzo.12015

Bell, A. M., Hankison, S. J., and Laskowski, K. L. (2009). The repeatability of behaviour: a meta-analysis. Anim. Behav. 77, 771-783. doi: $10.1016 /$ j.anbehav.2008.12.022

Bijma, P. (2014). The quantitative genetics of indirect genetic effects: a selective review of modelling issues. Heredity (Edinb). 112, 61-69. doi: 10.1038/hdy.2013.15

Bijma, P., Muir, W. M., and Van Arendonk, J. A. M. (2007a). Multilevel selection 1: quantitative genetics of inheritance and response to selection. Genetics 175, 277-288. doi: 10.1534/genetics.106.062711 ringing of birds, as part of the long-term monitoring of the population.

\section{AUTHOR CONTRIBUTIONS}

JM, JF, SK, and BD designed the study; JM, JF, SK, BD and many assistants carried out the fieldwork; JM analyzed the data; JM, JF, SK, LG, and BD drafted and critically revised the manuscript.

\section{FUNDING}

This work was funded by the Ministère de l'Enseignement Supérieur et de la Recherche (Ph.D. grant to JM), the Région Auvergne Rhône-Alpes (Explora'doc mobility grants), Uppsala Universitet (Stiftelsen research grant), the Kone Foundation (JF), the Emil Aaltonen Foundation (SK), the Estonian Research Council (grant PUT1474 to SK), the Swedish Research Council (LG), and the Centre National pour la Recherche Scientifique (PICS to BD).

\section{ACKNOWLEDGMENTS}

We thank the landowners from Gotland for access to the field site, all field workers in particular Laure Cauchard, Marion Germain, and Louise Riotte-Lambert, that contributed implementing the experiment and collecting data between 2012 and 2016, Pierre de Villemereuil for helpful discussions on statistical models, and Jere Tolvanen for helpful discussions during data preparation and analysis.

\section{SUPPLEMENTARY MATERIAL}

The Supplementary Material for this article can be found online at: https://www.frontiersin.org/articles/10.3389/fevo. 2017.00167/full\#supplementary-material

Bijma, P., Muir, W. M., Ellen, E. D., Wolf, J. B., and Van Arendonk, J. A. M. (2007b). Multilevel selection 2: estimating the genetic parameters determining inheritance and response to selection. Genetics 175, 289-299. doi: 10.1534/genetics.106.062729

Boulinier, T., McCoy, K. D., Yoccoz, N. G., Gasparini, J., and Tveraa, T. (2008). Public information affects breeding dispersal in a colonial bird: kittiwakes cue on neighbours. Biol. Lett. 4, 538-540. doi: 10.1098/rsbl.200 8.0291

Bouwman, A. C., Bergsma, R., Duijvesteijn, N., and Bijma, P. (2010). Maternal and social genetic effects on average daily gain of piglets from birth until weaning. J. Anim. Sci. 88, 2883-2892. doi: 10.2527/jas.2009-2494

Brommer, J. E., and Rattiste, K. (2008). "Hidden" reproductive conflict between mates in a wild bird population. Evolution 62, 2326-2333. doi: 10.1111/j.1558-5646.2008.00451.x

Caro, S. P., Charmantier, A., Lambrechts, M. M., Blondel, J., Balthazart, J., and Williams, T. D. (2009). Local adaptation of timing of reproduction: females are in the driver's seat. Funct. Ecol. 23, 172-179. doi: 10.1111/j.1365-2435.2008.01486.x

Charmantier, A., and Réale, D. (2005). How do misassigned paternities affect the estimation of heritability in the wild? Mol. Ecol. 14, 2839-2850. doi: 10.1111/j.1365-294X.2005.02619.x 
Charmantier, A., Garant, D., and Kruuk, L. E. B. (2014). Quantitative Genetics in the Wild. Oxford: Oxford University Press.

Dall, S. R. X. (2005). Defining the concept of public information. Science 308, 353c-356c. doi: 10.1126/science.308.5720.353c

Dall, S. R., Giraldeau, L.-A., Olsson, O., McNamara, J. M., and Stephens, D. W. (2005). Information and its use by animals in evolutionary ecology. Trends Ecol. Evol. (Amst). 20, 187-193. doi: 10.1016/j.tree.2005.0 1.010

Danchin, E., Boulinier, T., and Massot, M. (1998). Conspecific reproductive success and breeding habitat selection: implications for the study of coloniality. Ecology 79, 2415-2428. doi: 10.1890/0012-9658(1998)079[2415:CRSABH]2.0.CO;2

Danchin, E., Giraldeau, L.-A., and Cézilly, F. (2008). Behavioural Ecology. New York, NY: Oxford University Press.

Danchin, E., Giraldeau, L.-A., Valone, T. J., and Wagner, R. H. (2004). Public information: from nosy neighbors to cultural evolution. Science 305, 487-491. doi: $10.1126 /$ science. 1098254

Danchin, E., Heg, D., and Doligez, B. (2001). "Public information and breeding habitat selection," in Dispersal, eds J. Clobert, E. Danchin, A. A. Dhondt, and J. D. Nichols (Oxford: Oxford University Press), 243-258.

de Villemereuil, P., de, Gimenez, O., and Doligez, B. (2013). Comparing parent-offspring regression with frequentist and Bayesian animal models to estimate heritability in wild populations: a simulation study for Gaussian and binary traits. Methods Ecol. Evol. 4, 260-275. doi: 10.1111/2041-210 $\mathrm{X} .12011$

de Villemereuil, P., de, Schielzeth, H., Nakagawa, S., and Morrissey, M. (2016). General methods for evolutionary quantitative genetic inference from generalized mixed models. Genetics 204, 1281-1294. doi: 10.1534/genetics.115.186536

Dochtermann, N. A., Schwab, T., and Sih, A. (2015). The contribution of additive genetic variation to personality variation: heritability of personality. Proc. Biol. Sci. 282:20142201. doi: 10.1098/rspb.2014.2201

Dohm, M. R. (2002). Repeatability estimates do not always set an upper limit to heritability. Funct. Ecol. 16, 273-280. doi: 10.1046/j.1365-2435.2002.00621.x

Doligez, B., and Boulinier, T. (2008). "Habitat selection and habitat suitability preferences" in Encyclopedia of Ecology, eds S. E. Jorgensen and B. D. Fath (Oxford: Elsevier), 1810-1830.

Doligez, B., Cadet, C., Danchin, E., and Boulinier, T. (2003). When to use public information for breeding habitat selection? The role of environmental predictability and density dependence. Anim. Behav. 66, 973-988. doi: 10.1006/anbe.2002.2270

Doligez, B., Danchin, E., and Clobert, J. (2002). Public information and breeding habitat selection in a wild bird population. Science 297, 1168-1170. doi: $10.1126 /$ science. 1072838

Doligez, B., Danchin, E., Clobert, J., and Gustafsson, L. (1999). The use of conspecific reproductive success for breeding habitat selection in a non-colonial, hole-nesting species, the collared flycatcher. J. Anim. Ecol. 68, 1193-1206. doi: 10.1046/j.1365-2656.1999.0 0362.x

Doligez, B., Pärt, T., and Danchin, E. (2004b). Prospecting in the collared flycatcher: gathering public information for future breeding habitat selection? Anim. Behav. 67, 457-466. doi: 10.1016/j.anbehav.2003.0 3.010

Doligez, B., Pärt, T., Danchin, E., Clobert, J., and Gustafsson, L. (2004a). Availability and use of public information and conspecific density for settlement decisions in the collared flycatcher. J. Anim. Ecol. 41, 75-87. doi: $10.1111 / j .1365-2656.2004 .00782 . x$

Dugatkin, L. A., and Godin, J. G. J. (1993). Female mate copying in the guppy (Poecilia reticulata): age-dependent effects. Behav. Ecol. 4, 289-292. doi: 10.1093/behec o/4.4.289

Fidler, A. E., van Oers, K., Drent, P. J., Kuhn, S., Mueller, J. C., and Kempenaers, B. (2007). Drd4 gene polymorphisms are associated with personality variation in a passerine bird. Proc. R. Soc. B. Biol. Sci. 274, 1685-1691. doi: 10.1098/rspb.2007.0337

Forsman, J. T., and Seppänen, J.-T. (2011). Learning what (not) to do: testing rejection and copying of simulated heterospecific behavioural traits. Anim. Behav. 81, 879-883. doi: 10.1016/j.anbehav.2011.0 1.029
Forsman, J. T., and Thomson, R. L. (2008). Evidence of information collection from heterospecifics in cavity-nesting birds. Ibis 150, 409-412. doi: 10.1111/j.1474-919X.2007.00773.x

Forsman, J. T., Hjernquist, M. B., Taipale, J., and Gustafsson, L. (2008). Competitor density cues for habitat quality facilitating habitat selection and investment decisions. Behav. Ecol. 19, 539-545. doi: 10.1093/beheco/a rn005

Forsman, J. T., Kivelä, S. M., Jaakkonen, T., Seppänen, J. T., Gustafsson, L., and Doligez, B. (2014). Avoiding perceived past resource use of potential competitors affects niche dynamics in a bird community. BMC Evol. Biol. 14:175. doi: 10.1186/s12862-014-0175-2

Forsman, J. T., Seppänen, J.-T., and Mönkkönen, M. (2002). Positive fitness consequences of interspecific interaction with a potential competitor. Proc. R. Soc. B. 269, 1619-1623. doi: 10.1098/rspb.200 2.2065

Forsman, J. T., Seppänen, J.-T., Mönkkönen, M., Thomson, R. L., Kivelä, S. M., Krams, I., et al. (in press). Is it interspecific information use or aggression between putative competitors that steers the selection of nest-site characteristics? A reply to Slagsvold and Wiebe. J. Avian. Biol. doi: $10.1111 /$ jav.01558

Forsman, J. T., Seppänen, J.-T., and Nykänen, I. L. (2012). Observed heterospecific clutch size can affect offspring investment decisions. Biol. Lett. 8, 341-343. doi: 10.1098/rsbl.2011.0970

Forstmeier, W., Wagenmakers, E., and Parker, T. H. (2017). Detecting and avoiding likely false-positive findings - a practical guide. Biol. Rev. 92, 1941-1968. doi: $10.1111 /$ brv. 12315

Foucaud, J., Philippe, A.-S., Moreno, C., and Mery, F. (2013). A genetic polymorphism affecting reliance on personal versus public information in a spatial learning task in Drosophila melanogaster. Proc. Biol. Sci. 280:20130588. doi: $10.1098 / \mathrm{rspb} .2013 .0588$

Germain, R. R., Wolak, M. E., Arcese, P., Losdat, S., and Reid, J. M. (2016). Direct and indirect genetic and fine-scale location effects on breeding date in song sparrows. J. Anim. Ecol. 85, 1613-1624. doi: 10.1111/1365-265 6.12575

Greenwood, P. J. (1980). Mating systems, philopatry and dispersal in birds and mammals. Anim. Behav. 28, 1140-1162. doi: 10.1016/S0003-3472(80)80103-5

Gustafsson, L. (1986). Lifetime reproductive success and heritability: empirical support for Fisher's fundamental theorem. Am. Nat. 128, 761-764. doi: $10.1086 / 284601$

Hadfield, J. D. (2010). MCMC methods for multi-response generalized linear mixed models: the MCMCglmm R package. J. Stat. Softw. 33, 1-22. doi: $10.18637 /$ jss.v033.i02

Hadfield, J. D. (2014). MCMCglmm Course Notes. Available online at: https://cran. r-project.org/web/packages/MCMCglmm/index.html

Hall, M. D., Lailvaux, S. P., and Brooks, R. C. (2013). Sex-specific evolutionary potential of pre- And postcopulatory reproductive interactions in the field cricket, Teleogryllus commodus. Evolution 67, 1831-1837. doi: 10.1111/evo.12067

Jaakkonen, T., Kari, A., and Forsman, J. T. (2013). Flycatchers copy conspecifics in nest-site selection but neither personal experience nor frequency of tutors have an effect. PLoS ONE 8:e60395. doi: 10.1371/journal.pone.0060395

Jaakkonen, T., Kivela, S. M., Meier, C. M., and Forsman, J. T. (2015). The use and relative importance of intraspecific and interspecific social information in a bird community. Behav. Ecol. 26, 55-64. doi: 10.1093/beheco/a rul44

Kendal, R. L., Coolen, I., and Laland, K. N. (2004). The role of conformity in foraging when personal and social information conflict. Behav. Ecol. 15, 269-277. doi: 10.1093/beheco/arh008

Kendal, R. L., Coolen, I., Bergen, Y., van, and Laland, K. N. (2005). Trade-offs in the adaptive use of social and asocial learning. Adv. Study Behav. 35, 333-379. doi: 10.1016/S0065-3454(05)35008-X

Kivelä, S. M., Seppänen, J.-T., Ovaskainen, O., Doligez, B., Gustafsson, L., Mönkkönen, M., et al. (2014). The past and the present in decision-making: the use of conspecific and heterospecific cues in nest site selection. Ecology 95, 3428-3439. doi: 10.1890/13-2103.1

Kniel, N., Dürler, C., Hecht, I., Heinbach, V., Zimmermann, L., and Witte, K. (2015). Novel mate preference through mate-choice copying in zebra finches: sexes differ. Behav. Ecol. 26, 647-655. doi: 10.1093/beheco/aru241 
Kruuk, L. E. B. (2004). Estimating genetic parameters in natural populations using the "animal model." Philos. Trans. R. Soc. Lond. B. Biol. Sci. 359, 873-890. doi: 10.1098/rstb.2003.1437

Kurvers, R. H., van Oers, K., Nolet, B. A., Jonker, R. M., Van Wieren, S. E., Prins, H. H. T., et al. (2010). Personality predicts the use of social information. Ecol. Lett. 13, 829-837. doi: 10.1111/j.1461-0248.2010.0 1473.x

Loukola, O. J., Seppänen, J.-T., and Forsman, J. T. (2012). Intraspecific social information use in the selection of nest site characteristics. Anim. Behav. 83, 629-633. doi: 10.1016/j.anbehav.2011.12.004

Loukola, O. J., Seppänen, J.-T., Krams, I., Torvinen, S. S., and Forsman, J. T. (2013). Observed fitness may affect niche overlap in competing species via selective social information use. Am. Nat. 182, 474-483. doi: 10.1086/6 71815

Lynch, M., and Walsh, B. (1998). Genetics and Analysis of Quantitative Traits. Sunderland, MA: Sinauer Associates.

Marchetti, C., and Drent, P. (2000). Individual differences in the use of social information in foraging by captive great tits. Anim. Behav. 60, 131-140. doi: $10.1006 /$ anbe. 2000.1443

McAdam, A. G., Garant, D., and Wilson, A. J. (2014). "The effects of others' genes: maternal and other indirect genetic effects," in Quantitative Genetics in the Wild, eds A. Charmantier, D. Garant, and L. E. B. Kruuk (Oxford: Oxford University Press), 84-103.

McAdam, A. G., Boutin, S., Reale, D., and Berteaux, D. (2002). Maternal effects and the potential for evolution in a natural population of animals. Evolution 56, 846-851. doi: 10.1111/j.0014-3820.2002.tb 01396.x

Meffert, L. M., Hicks, S. K., and Regan, J. L. (2002). Nonadditive genetic effects in animal behavior. Am. Nat. 160 (Suppl.), S198-S213. doi: 10.1086/342896

Merilä, J., and Sheldon, B. C. (1999). Genetic architecture of fitness and nonfitness traits: empirical patterns and development of ideas. Heredity (Edinb). 83, 103-109. doi: 10.1046/j.1365-2540.1999.00585.x

Merilä, J., and Wiggins, D. A. (1995). Interspecific competition for nest holes causes adult mortality in the collared flycatcher. Condor 97, 445-450. doi: $10.2307 / 1369030$

Mery, F., and Kawecki, T. J. (2002). Experimental evolution of learning ability in fruit flies. Proc. Natl. Acad. Sci. U.S.A. 99, 14274-14279. doi: 10.1073/pnas.222371199

Moore, A. J., Brodie, E. D., and Wolf, J. B. (1997). Interacting phenotypes and the evolutionary process: I. Direct and indirect genetic effects of social interactions. Evolution 51, 1352-1362. doi: 10.1111/j.1558-5646.1997.tb 01458.x

Morrissey, M. B., and Wilson, A. J. (2010). Pedantics: an R package for pedigreebased genetic simulation and pedigree manipulation, characterization and viewing. Mol. Ecol. Res. 10, 711-719. doi: 10.1111/j.1755-0998.2009.02817.x

Mundry, R., and Nunn, C. L. (2009). Stepwise model fitting and statistical inference: turning noise into signal pollution. Am. Nat. 173, 119-123. doi: $10.1086 / 593303$

Nakagawa, S., and Schielzeth, H. (2010). Repeatability for Gaussian and nonGaussian data: a practical guide for biologists. Biol. Rev. 85, 935-956. doi: 10.1111/j.1469-185X.2010.00141.x

Parejo, D. (2016). Informational mismatches: a neglected threat of climate change to interspecific interactions. Front. Ecol. Evol. 4:31. doi: $10.3389 /$ fevo.2016.00031

Pärt, T. (1995). The importance of local familiarity and search costs for age- and sex-biased philopatry in the collared flycatcher. Anim. Behav. 49, 1029-1038. doi: 10.1006/anbe.1995.0132

Quinn, J. L., Charmantier, A., Garant, D., and Sheldon, B. C. (2006). Data depth, data completeness, and their influence on quantitative genetic estimation in two contrasting bird populations. J. Evol. Biol. 19, 994-1002. doi: $10.1111 /$ j.1420-9101.2006.01081.x

R Development Core Team (2011). R: A Language and Environment for Statistical Computing. Vienna: $\mathrm{R}$ foundation for Statistical Computing.
Reed, J. M., Boulinier, T., Danchin, E., and Oring, L. W. (1999). "Informed dispersal," in Current Ornithology, eds V. Nolan, E. D. Ketterson, and C. F. Thompson (Boston, MA: Springer), 189-259.

Roff, D. A. (1997). Evolutionary Quantitative Genetics. New York, NY: Chapman and Hall. doi: 10.1007/978-1-4615-4080-9

Samplonius, J. M., and Both, C. (2017). Competitor phenology as a social cue in breeding site selection. J. Anim. Ecol. 86, 615-623. doi: 10.1111/1365-2656.12640

Seppänen, J.-T., and Forsman, J. T. (2007). Interspecific social learning: novel preference can be acquired from a competing species. Curr. Biol. 17, 1248-1252. doi: 10.1016/j.cub.2007.06.034

Seppänen, J.-T., Forsman, J. T., Mönkkönen, M., and Thomson, R. L. (2007). Social information use is a process across time, space, and ecology, reaching heterospecifics. Ecology 88, 1622-1633. doi: 10.1890/06-1757.1

Seppänen, J.-T., Forsman, J. T., Mönkkönen, M., Krams, I., and Salmi, T. (2011). New behavioural trait adopted or rejected by observing heterospecific tutor fitness. Proc. R. Soc. B. Biol. Sci. 278, 1736-1741. doi: 10.1098/rspb.2010.1610

Sheldon, B. C., and Ellegren, H. (1999). Sexual selection resulting from extrapair paternity in collared flycatchers. Anim. Behav. 57, 285-298. doi: 10.1006/anbe.1998.0968

Stirling, D. G., Réale, D., and Roff, D. A. (2002). Selection, structure and the heritability of behaviour. J. Evol. Biol. 15, 277-289. doi: 10.1046/j.1420-9101.2002.00389.x

Svensson, L. (1992). Identification Guide to European Passerines. London: British Trust for Ornithology.

Teplitsky, C., Mills, J. A., Yarrall, J. W., and Merilä, J. (2010). Indirect genetic effects in a sex-limited trait: the case of breeding time in red-billed gulls. J. Evol. Biol. 23, 935-944. doi: 10.1111/j.1420-9101.2010.01959.x

Trivers, R. L. L. (1972). "Parental investment and sexual selection," in Sexual Selection and the Descent of Man, ed B. Campbell (Chicago, IL: Aldine), 136-179.

Valone, T. J. (2007). From eavesdropping on performance to copying the behavior of others: a review of public information use. Behav. Ecol. Sociobiol. 62, 1-14. doi: 10.1007/s00265-007-0439-6

van Bergen, Y., van, Coolen, I., and Laland, K. N. (2004). Nine-spined sticklebacks exploit the most reliable source when public and private information conflict. Proc. Biol. Sci. 271, 957-962. doi: 10.1098/rspb.2004.2684

Wilson, A. J. (2008). Why h ${ }^{2}$ does not always equal VA/VP? J. Evol. Biol. 21, 647-650. doi: 10.1111/j.1420-9101.2008.01500.x

Wilson, A. J., Réale, D., Clements, M. N., Morrissey, M. M., Postma, E., Walling, C. A., et al. (2010). An ecologist's guide to the animal model. J. Anim. Ecol. 79, 13-26. doi: 10.1111/j.1365-2656.2009.01639.x

Wolak, M. E. (2012). nadiv: an R package to create relatedness matrices for estimating non-additive genetic variances in animal models. Methods Ecol. Evol. 3, 792-796. doi: 10.1111/j.2041-210X.2012.00213.x

Wolak, M. E., and Keller, L. F. (2014). "Dominance genetic variance and inbreeding in natural populations," in Quantitative Genetics in the Wild, eds A. Charmantier, D. Garant, and L. E. B. Kruuk (Oxford: Oxford University Press), 104-127.

Wolf, J. B., Brodie, E. D. B. III., Cheverud, J. M., Moore, A. J., and Wade, M. J. (1998). Indirect genetic effects. Science 13, 64-69.

Conflict of Interest Statement: The authors declare that the research was conducted in the absence of any commercial or financial relationships that could be construed as a potential conflict of interest.

Copyright (๑) 2018 Morinay, Forsman, Kivelä, Gustafsson and Doligez. This is an open-access article distributed under the terms of the Creative Commons Attribution License (CC BY). The use, distribution or reproduction in other forums is permitted, provided the original author(s) and the copyright owner are credited and that the original publication in this journal is cited, in accordance with accepted academic practice. No use, distribution or reproduction is permitted which does not comply with these terms. 